\title{
Regulation of Gene Expression in the Bovine Mammary Gland by Ovarian Steroids ${ }^{1}$
}

\author{
E. E. Connor, ${ }^{* 2}$ M. J. Meyer, $†$ R. W. Li, ${ }^{*}$ M. E. Van Amburgh, $\ddagger$ Y. R. Boisclair, $\ddagger$ and A. V. Capuco* \\ *Bovine Functional Genomics Laboratory, USDA, ARS, Beltsville, MD 20705-2350 \\ †Mammary Biology and Tumorigenesis Laboratory, National Institutes of Health, National Cancer Institute, Bethesda, MD 20892-4254 \\ ‡Department of Animal Science, Cornell University, Ithaca, NY 14853-4801
}

\begin{abstract}
It is well established that estrogen is required for mammary epithelial cell proliferation and ductal development in the growing animal, and that lobuloalveolar development during gestation is dependent on progesterone. The effects of these steroid hormones on gene expression in the mammary gland are mediated primarily by their respective nuclear hormone receptors, which function as hormone-bound transcription factors. To gain insight into how estrogen and progesterone regulate mammary gland growth and function in cattle, we and others have characterized the expression patterns of their cognate nuclear hormone receptors in the bovine mammary gland throughout development, pregnancy, and lactation. This work has identified a lack of expression of estrogen receptor $\beta$ and a greater abundance of progesterone receptor during lactation in the bovine mammary gland, compared with the rodent gland. We speculate that interactions among the estrogen receptor isoforms that regulate progesterone receptor expression may contribute to these species differences. Further, demonstrated expression of substantial quantities of estrogen receptor within the prepubertal bovine mammary fat pad, along with coordinated insulin-like growth factor-I expression, suggests that this tissue may stimulate parenchymal growth via an estrogen-responsive paracrine mechanism. In addition, the recent availability of bovine genomic sequence information and microarray technologies has permitted the study of global gene expression in the mammary gland in response to the steroid environment. We have identified more than 100 estrogen-responsive genes, of which the majority are novel estrogen gene targets. Estrogeninduced changes in gene expression were consistent with increased mammary epithelial cell proliferation,
\end{abstract}

Received July 24, 2006.

Accepted October 26, 2006.

${ }^{1}$ Presented at the ADSA-ASAS Joint Annual Meeting, Minneapolis, MN, July 2006.

${ }^{2}$ Corresponding author: econnor@anri.barc.usda.gov increased extracellular matrix turnover in parenchyma, and increased extracellular matrix deposition in the fat pad. A comparison of estrogen-responsive genes in the mammary glands of humans, mice, and cattle suggests considerable variation among species, as well as potential differences in regulatory elements in common estrogen receptor gene targets. Continuing studies using advanced molecular techniques should assist in elucidating the complex regulation of mammary function at the transcript level.

Key words: gene expression, mammary gland, ovarian steroid

\section{INTRODUCTION}

The mammary gland is a complex organ of various tissue and cell types that will undergo multiple stages of growth, differentiation, secretory activity, and involution during the lifetime of a female mammal. These physiological stages are regulated at the systemic and local levels, both of which are coordinated heavily by the ovarian steroids estrogen and progesterone. Considerable advances in our knowledge of steroidal hormone regulation of mammary function have been made through morphological examination of the normal gland, ablation and replacement studies, surgical transplantation studies, hormonal manipulation of mammary cells in vitro, and most recently, studies of knockout mouse models. The availability of DNA sequence information of the human, mouse, and now the bovine genomes has greatly facilitated the study of steroid hormone regulation of mammary gland biology at the gene level.

Currently, technologies such as laser capture microdissection and gene transcript profiling by microarray and quantitative real-time reverse transcription PCR are being applied to investigate gene expression in the mammary gland during normal growth and development. The goal of this review is to provide a summary of the current knowledge of local regulation of gene expression in the mammary gland by the ovarian hormones, estrogen and progesterone, and to highlight 
some recent studies conducted in the bovine mammary gland using molecular and genomic approaches. Where appropriate, comparisons are made among rodent, human, and ruminant species. Ultimately, knowledge of gene regulation in the mammary gland should facilitate the development of methods to increase milk yield and lactation persistency, reduce the length of the dry period between successive lactations, and improve the efficiency of dairy production.

\section{Roles of Estrogen and Progesterone in Normal Mammary Growth and Development}

Normal development and function of the mammary gland is dependent on the ovarian hormones estrogen and progesterone, as well as the coordinated action of many other hormones, including prolactin, growth hormone, placental lactogen, thyroid hormones, glucocorticoids, and oxytocin (Cowie et al., 1980; Forsyth, 1986; Tucker, 2000; Neville et al., 2002). The extent to which each hormone influences mammary growth and lactation depends on the species being investigated. Much of our knowledge of the roles of estrogen and progesterone has resulted from classical endocrine ablation and replacement studies in rodents. However, early studies in cattle demonstrated that ovariectomy in the prepubertal heifer impaired mammary growth and that estrogen replacement could reverse this inhibitory effect (Wallace, 1953). Similarly, local ablation of estrogen action in the mammary gland using antiestrogen implants has been shown to inhibit epithelial cell proliferation and ductal development in the endocrine-intact mouse (Silberstein et al., 1994), suggesting the direct action of estrogen on mammary cell proliferation. Despite this similarity between cattle and mice, it should be noted that ovariectomy in prepubertal sheep did not impair prepubertal mammary development (Ellis et al., 1998) and that the mechanisms contributing to these species differences have yet to be elucidated.

In addition to the effects of ovarian steroid removal, estrogen treatment alone or in combination with progesterone in the intact prepubertal heifer has been shown to stimulate the proliferation of mammary epithelial and endothelial cell populations as well as fibroblasts in close proximity to epithelial cells, whereas progesterone treatment alone has no effect on prepubertal mammary cell proliferation (Woodward et al., 1993). Progesterone treatment in the peripubertal mouse enhances ductal morphogenesis by increasing sidebranching of mammary ducts and terminal end bud formation (Hovey et al., 2002), whereas considerable ductal branching occurs in ruminants in the absence of progesterone (Capuco et al., 2002a). In the nonpregnant, nonlactating cow, a combined estrogen and pro- gesterone treatment was shown to stimulate mammary epithelial cell differentiation and lobuloalveolar development (Turner et al., 1956). Thus, both steroid hormones appear to play substantial roles in mammary growth and development. However, because of systemic effects of these hormones and interactions between their signaling pathways, determination of the individual roles of estrogen and progesterone in mammary gland development is difficult.

Creation of genetically modified mice lacking critical genes (knockouts) in the estrogen- and progesteronesignaling pathways has greatly facilitated our understanding of the roles of estrogen and progesterone in mammary development. First, the observations that mice lacking the estrogen receptor (ERKO mice), which mediates estrogen action, and mice lacking aromatase (ARKO mice), the enzyme responsible for estrogen synthesis, maintain a prepubertal mammary ductal phenotype through adulthood (Lydon et al., 2000; Walker and Korach, 2004) clearly demonstrate the critical role of estrogen in pubertal mammary ductal development. Second, the requirement for progesterone in the process of ductal development in the young animal is ruled out by the fact that mammary ducts of mice lacking the progesterone receptor (PRKO mice), which therefore cannot receive progesterone signals, develop normally (Lydon et al., 2000). During pregnancy, however, progesterone is necessary for mammary growth and differentiation, as shown by experiments in which mammary tissues of PRKO mice transplanted into wild-type mice fail to undergo normal ductal side-branching and lobuloalveolar development in pregnancy (Lydon et al., 2000). In addition, estrogen appears to be required for ductal side-branching and lobuloalveolar development, because ERKO mice can only be induced to undergo these developmental stages with treatment of estrogen + progesterone, and not progesterone treatment alone (Bocchinfuso et al., 2000). Bocchinfuso et al. (2000) proposed that these effects of estrogen are not direct but are mediated by an indirect mechanism, such as induction of mammary progesterone receptor (PR) expression. Together, the results of these and other studies have established the general roles of estrogen as a critical mediator of mammary epithelial cell proliferation and ductal development in the growing animal, and progesterone as a stimulator of lobuloalveolar differentiation in the pregnant gland.

\section{Nuclear Hormone Receptors: Mediators of Estrogen and Progesterone Action}

The actions of estrogen and progesterone are mediated, at least in part, by their cognate nuclear hormone receptors estrogen receptor (ER) and PR, respectively. 
Members of this family of hormone receptors function as ligand-bound transcription factors that regulate expression of specific downstream gene targets. Because of their central role in mediating the effects of estrogen and progesterone on gene expression, the structure and mechanisms of action of the nuclear hormone receptors are discussed briefly. More thorough reviews are provided by Kushner et al. (2000), Aranda and Pascual (2001), Fannon et al. (2001), and Lazar (2002).

Members of the nuclear hormone receptor family share a common structure, namely, 6 functional domains labeled A through $\mathrm{F}$. The $\mathrm{A} / \mathrm{B}$ domain $\left(\mathrm{NH}_{2}\right.$ terminus) is the most variable region and is generally the region that differentiates the multiple isoforms of the steroid hormone receptors (Aranda and Pascual, 2001). The $\mathrm{C}$ domain is the most conserved region of the nuclear hormone receptor family and contains the DNAbinding domain, or region that binds to the promoter of target genes (Aranda and Pascual, 2001; Lazar, 2002). The $\mathrm{C}$ domain is also a region important for receptor dimerization (Aranda and Pascual, 2001; Fannon et al., 2001). The D domain is poorly conserved across the nuclear hormone receptors and serves as a linker of variable length between the $\mathrm{C}$ and $\mathrm{E}$ domains (Aranda and Pascual, 2001). Last, the ligand specificity of the steroid hormone receptors is determined by the ligand-binding domain, or $\mathrm{E}$ domain. This domain interacts with the steroid ligand, resulting in a conformational change in the receptor (Aranda and Pascual, 2001) that is recognized by transcriptional coactivators or corepressors (Lazar, 2002). No specific regulatory functions have been identified for the $\mathrm{F}$ domain located within the $-\mathrm{COOH}$ terminus of the protein (Fannon et al., 2001; Lazar, 2002).

The mechanisms of action of the steroid hormone receptors are illustrated in Figure 1. In the classical model, steroid hormone receptors are located in close association or within the cell nucleus, where they dimerize upon ligand binding and directly bind to specific DNA sequences in target gene promoters known as hormone response elements. The ligand-bound receptors then either recruit coactivators, resulting in enhanced target gene transcription, or recruit corepressors that suppress gene transcription (Aranda and Pascual, 2001; Fannon et al., 2001; Lazar, 2002). Nonclassical transcriptional activity has also been suggested for ER activation of target gene promoters via protein-protein interactions. In this model, the ligand-bound receptor may act through multiple alternative response elements, such as activator protein-1 or cyclic AMP response element (CRE)-like elements, which do not bind ER but instead bind other transcription factors (Kushner et al., 2000). Such pathways have been shown in ER activation of stimulators of mammary cell proliferation,
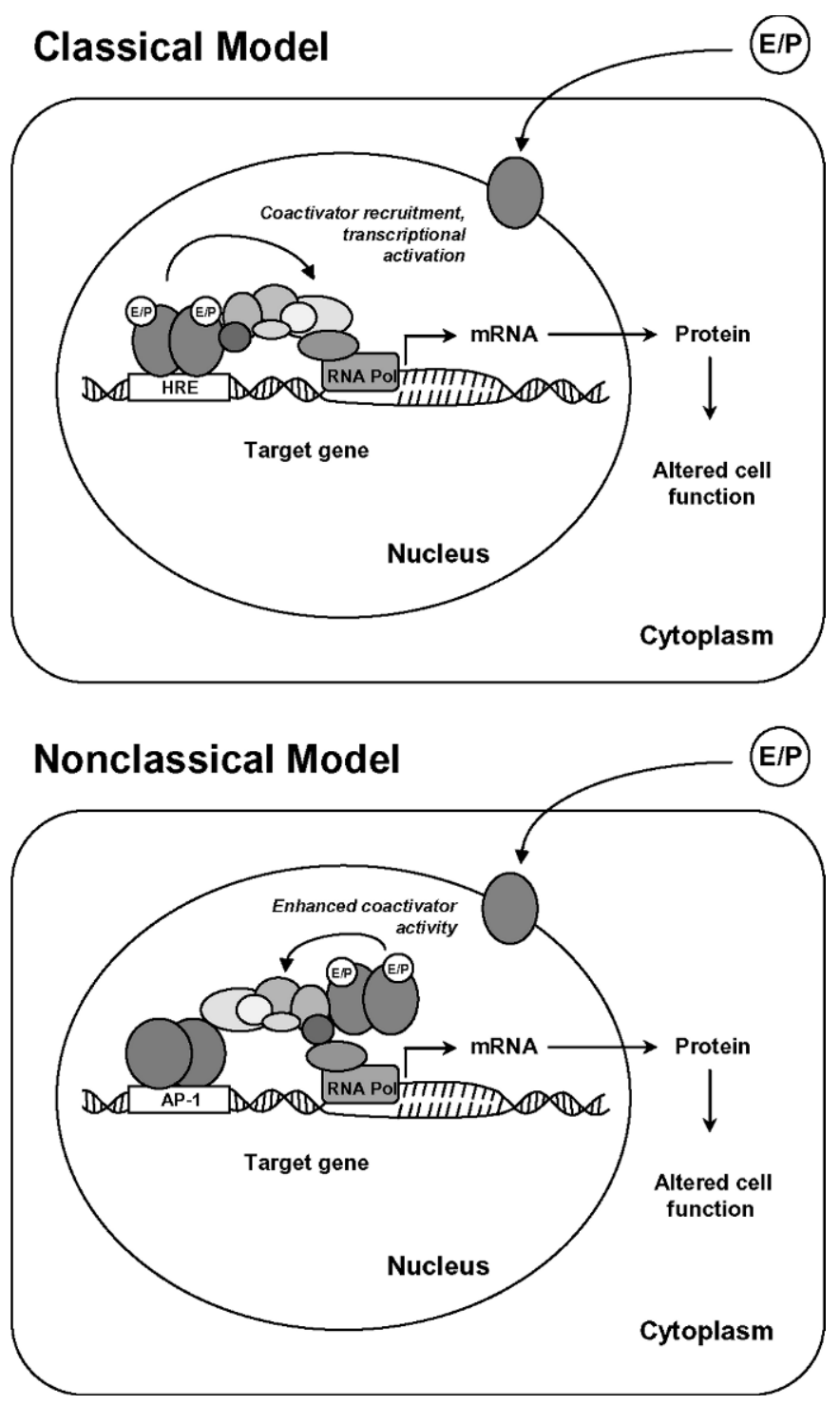

Figure 1. Mechanisms of steroid hormone receptor action on gene transcription. AP-1 = activator protein- 1 response element; $\mathrm{E}=$ estrogen $; \mathrm{HRE}=$ hormone response element $\mathrm{P}=$ progesterone $; \mathrm{RNA} \mathrm{Pol}=$ RNA polymerase.

including IGF-I (Umayahara et al., 1994) and cyclin D1 (Liu et al., 2002).

Hormone response elements in target genes generally consist of 2 repeated consensus sequences of 6 nucleotides, each called half-sites. The half-sites are spaced a specific distance apart and are arranged in a particular orientation. For example, the consensus sequence for the ER response element consists of 2 inverted repeats spaced 3 nucleotides apart (Aranda and Pascual, 2001), for example, AGGTCA-NNN-TGACCT, where each half-site binds to a monomer of the dimerized receptor. Thus, the specificity of the receptor-DNA interaction is determined by the sequence of the half-sites on target 
gene promoters and the spacing between them. Transcriptional effects on target genes are then mediated by the distinct proteins that are recruited to the hormonereceptor-DNA complex. For instance, coactivators enhance the transcription of target genes by facilitating the unwinding of target gene DNA and promoting RNA polymerase II accessibility (Lazar, 2002). Currently, the mechanisms of action of corepressors are less clear and may involve recruitment of enzymes that promote compaction of genomic DNA, ultimately suppressing transcriptional activity (Lazar, 2002). Therefore, the genomic responses of a particular tissue, such as the mammary gland to estrogen and progesterone, depend on multiple factors including, but not limited to, the following: 1) the concentration or availability of the steroid hormone; 2) the presence of the appropriate target receptor(s); 3) the assembly of specific transcription factors and associated machinery required for gene expression; and 4) the presence of competing receptors or receptor subtypes, which is discussed in greater detail in the following section.

The most current models of steroid receptor action also include membrane-bound forms of receptors that may signal via intracellular second messengers and result in rapid, nongenomic steroidal effects. Evidence for these effects is provided by immediate responses (within minutes) to steroid treatment, as well as cellular responses to steroids in the presence of inhibitors of transcription or protein synthesis. Furthermore, positive staining for specific receptors such as ER $\alpha$ within the plasma membrane of cultured normal and cancerous cells and the presence of membrane-associated PR on human spermatozoa (Falkenstein et al., 2000) and the bovine ovary (Rae et al., 1998) have been described. Specifically, mRNA consistent with plasma membraneexpressed G protein-coupled receptors for progesterone (mPR) have been cloned from a number of vertebrate species (Zhu et al., 2003), and G protein-coupled receptors for estrogen, including GPR30, have been characterized in human breast cancer cells (Thomas et al., 2005) and rat neurons (Funakoshi et al., 2006). Despite these findings, there is debate regarding the relevance of steroid membrane receptors and the occurrence of immediate cellular responses to steroid hormone treatment under normal physiological conditions (Warner and Gustafsson, 2006). Regardless, nonclassical and nongenomic effects of ovarian steroid hormones will surely be an area of considerable investigation in future studies of steroid action and may have implications for normal mammary gland function and development. For additional information on the nongenomic effects of steroid hormones, see Falkenstein et al. (2000), Schmidt et al. (2000), and Manavathi and Kumar (2006).

\section{Distribution and Function of ER and PR Isoforms}

The specific transcriptional responses of a tissue to estrogen or progesterone are influenced by the distribution of their receptors among its various cell types. In addition, multiple subtypes or isoforms of ER and PR have been identified as having unique effects on target gene transcription that permit diversity in cellular responses to the same ligand. Two isoforms of ER have been identified, referred to as $\operatorname{ER} \alpha$ and $\operatorname{ER} \beta$, that are transcribed from 2 separate genes but that share a high degree of similarity in their ligand-binding and DNAbinding domains. In addition, splice variants of $\operatorname{ER} \beta$ have been described in humans and rodents (Saji et al., 2001,2002 ), and $2 \mathrm{ER} \beta$ isoforms have been detected in the mammary gland of cattle (Schams et al., 2003). Similarly, there are 2 primary receptor isoforms for PR, referred to as PR-A and PR-B, that are transcribed from 2 separate promoters of the same gene in humans and rats (Kastner et al., 1990; Kraus et al., 1993) and from alternative start sites of a single transcript in chickens (Fannon et al., 2001). The PR-A and PR-B isoforms differ only in that PR-A is truncated at the amino terminus. Additional PR transcript variants labeled PR-C, PR-S, and PR-T have been characterized in human reproductive tissues (Wei et al., 1990; Taylor et al., 2006), and evidence for PR-C has been demonstrated in the bovine mammary gland and endometrium (Schams et al., 2003).

In vitro studies have shown that PR-A and PR-B can dimerize as homodimers or as heterodimers, and under the appropriate conditions, PR-A can function as a dominant repressor of PR-B (Conneely et al., 2001). Likewise, because PR-C lacks transcriptional activity, it has been proposed that its presence may reduce activity of the PR-A and PR-B isoforms. On the contrary, Wei et al. (1996) found that PR-A and PR-B transcriptional activity increased in the presence of $\mathrm{PR}-\mathrm{C}$ and that the enhancement could be via recruitment of transcriptional activators (Wei et al., 1997). Evidence also suggests that a specific PR-A:PR-B ratio is required for normal mammary gland development in that human breast cancer cells have altered receptor ratios compared with normal cells (Anderson, 2002). Transgenic mice that overexpress either PR-A or PR-B also exhibit abnormal ductal side-branching and proliferation (Shyamala et al., 1999). In terms of $\mathrm{ER}$ isoforms, $\mathrm{ER} \beta$ may act as a repressor of $\mathrm{ER} \alpha$ activation of target genes. For instance, $\mathrm{ER} \alpha-\mathrm{ER} \beta$ heterodimers have been shown to have lower transcriptional activity than $\mathrm{ER} \alpha$ homodimers and can therefore modulate estrogen action (Hall and McDonnell, 1999). Thus, because steroid receptor isoforms exhibit differential transcriptional activities, 
Table 1. Localization of the estrogen receptor (ER) isoforms and progesterone receptor $(\mathrm{PR})$ among cell types within primate, mouse, and bovine mammary glands, and relative ratios of the PR isoforms

\begin{tabular}{|c|c|c|c|c|c|}
\hline Species & $\operatorname{ER} \alpha$ & $\mathrm{ER} \beta$ & PR & $\begin{array}{l}\mathrm{PR} \text { isoform } \\
\text { ratio A:B }\end{array}$ & References \\
\hline Human & Luminal epithelial cells & $\begin{array}{l}\text { Luminal epithelial and } \\
\text { myoepithelial cells, } \\
\text { fibroblasts, and stromal } \\
\text { cells }\end{array}$ & Luminal epithelial cells & $1: 1$ & $\begin{array}{l}\text { Anderson (2002) } \\
\text { Spiers et al. (2002) } \\
\text { Anderson and Clarke (2004) }\end{array}$ \\
\hline Monkey & Epithelial cells & $\begin{array}{l}\text { Epithelial and myoepithelial } \\
\text { cells, fibroblasts }\end{array}$ & $\begin{array}{l}\text { Epithelial cells, a } \\
\text { few stromal cells }\end{array}$ & $1: 1$ & Cheng et al. (2005) \\
\hline Cow & $\begin{array}{l}\text { Epithelial cells, some } \\
\text { adipocytes of the fat pad, } \\
\text { some fibroblasts }\end{array}$ & $\begin{array}{l}\text { Very low abundance by } \\
\text { reverse transcription PCR, } \\
\text { not detectable by } \\
\text { immunohistochemistry }\end{array}$ & $\begin{array}{l}\text { Epithelial cells, some } \\
\text { stromal and vascular } \\
\text { cells, fat pad }\end{array}$ & $3: 1$ & $\begin{array}{l}\text { Pfaffl et al. (2001) } \\
\text { Capuco et al. (2002a) } \\
\text { Schams et al. (2003) } \\
\text { Connor et al. (2005) } \\
\text { Meyer et al. (2006, } \\
\text { unpublished data) }\end{array}$ \\
\hline
\end{tabular}

the relative abundance of each could alter the effects of estrogen and progesterone on target gene transcription.

The distribution and abundance of the ER isoforms and PR have been studied in several species and tissues, including human (Anderson, 2002), monkey (Cheng et al., 2005), rodent (Fendrick et al., 1998; Hovey et al., 2001; Shyamala et al., 2002), and bovine (Pfaffl et al., 2001; Capuco et al., 2002a; Schams et al., 2003; Connor et al., 2005) mammary glands. Table 1 summarizes the localization of the ER isoforms and PR among cell types within primate, mouse, and bovine mammary glands and the relative ratios of the PR-A and PR-B isoforms in each species. It is apparent that regulation of the receptors differs across species. For instance, $\operatorname{ER} \beta$ is expressed in multiple cell types in rodents and primates but is relatively absent in the bovine gland. Studies of $\operatorname{ER} \beta$ knockout mice indicate that $\operatorname{ER} \beta$ is not required to mediate the effects of estrogen on mammary development, because these mice exhibit normal ductal morphogenesis (Walker and Korach, 2004). However, it has been suggested that $\mathrm{ER} \beta$ or its splice variants can act as dominant repressors of $\mathrm{ER} \alpha$ and inhibit the stimulatory effects of estrogen on expression of PR during lactation (Saji et al., 2001). Examinations of ER and PR expression across developmental stages within the mammary gland illustrate that PR is typically not expressed during lactation in the murine gland (Shyamala et al., 1990; Hovey et al., 2001) but is expressed in significant quantities in the bovine gland during lactation (Capuco et al., 1982; Schams et al., 2003; Connor et al., 2005), and may be increased with concurrent pregnancy (Connor et al., 2005). Interestingly, $P R$ is expressed in the mammary gland of the lactating, pregnant mouse (Capuco et al., 2002b). We have suggested that the lack of $\mathrm{ER} \beta$ expression in the bovine mammary gland may permit PR expression during lactation in the cow (Connor et al., 2005), whereas the high levels of $\mathrm{ER} \beta$ variants during lactation in the rodent gland inhibit PR expression. On the contrary, recent work by Cheng et al. (2005) in the rhesus monkey indicates a lack of both $\operatorname{ER} \beta$ and $\mathrm{PR}$ proteins during lactation, suggesting that $\operatorname{ER} \beta$ does not contribute to PR suppression during lactation in primates. Additional study is needed to clearly delineate the genetic mechanisms contributing to these species differences.

Little is known about expression patterns of the distinct $\mathrm{PR}$ isoforms in the mammary gland, although differential expression of the PR-A, PR-B, and PR-C isoforms was demonstrated across developmental stages of the bovine by Western blotting (Schams et al., 2003), and ratios of the PR-A:PR-B isoforms appear to vary with developmental stage in the mouse gland and across species (Table 1). Both isoforms exhibit transcriptional activity but can differ in their specific gene targets (Anderson, 2002). The recent development of $\mathrm{PR}$ isoform-specific knockout mice illustrated that PR$\mathrm{A}$ is not required for normal mammary development but that PR-B is essential for ductal side-branching and lobuloalveolar development (Mulac-Jericevic and Conneely, 2004).

Clearly, much work is needed to determine the distinct mechanisms contributing to variation across species in steroid receptor expression and function in the mammary gland. In cattle, the development of antibodies and molecular probes to detect the specific isoforms (e.g., PR-A vs. PR-B) of the steroid receptors is needed to fully characterize their interactions at the transcript and protein levels. Future development of isoform-specific receptor modulators should assist in elucidating the roles of each isoform in mediating steroid hormone 
action in the mammary gland. Such modulators may ultimately serve as a means to manipulate mammary development and function in dairy animals, or as therapeutics for breast cancer treatment in humans.

\section{Roles of Mammary Parenchyma vs. Stroma}

In discussing the regulation of gene expression during normal mammary gland growth and development, it is critical to keep in mind that the gland is not a homogeneous organ but a mixture of cell types and tissues. For instance, the mammary parenchyma consists of the secretory epithelium, myoepithelium, ductal and alveolar cells, and surrounding supporting tissue, referred to as the stroma. The stroma too is a complex consisting of matrix proteins such as collagen and laminin, and cellular components including adipocytes, fibroblasts, and immune cells. These components likely vary in their contribution to processes such as ductal proliferation and modulation of gene expression, although the specific roles of each have yet to be determined.

A number of studies have demonstrated critical differences between the mammary stroma and epithelium in terms of their roles in normal mammary development (reviewed by Woodward et al., 1998; Silberstein, 2001), their expression of ER and PR (reviewed by Fendrick et al., 1998; Anderson and Clarke, 2004), and variation in morphology and function across species (reviewed by Hovey et al., 1999). Most studies investigating stromalepithelial interactions have focused on the mouse mammary gland and have benefited from the availability of gene knockout models, although limited studies of normal primate and bovine mammary glands have provided some insight into the roles of the stromal and parenchymal (or epithelial) compartments in other species.

Cunha et al. (1997) proposed that stromal ER $\alpha$, rather than epithelial $\mathrm{ER} \alpha$, is critical for ductal development in the mouse, based on surgical transplantation studies in which stroma from ERKO mice was combined with epithelial cells from wild-type mice, or stroma from wild-type mice was combined with epithelial cells from ERKO mice. The hybrid tissues were then transplanted under the kidney capsule of a recipient mouse and observed for ductal growth. No ductal growth resulted in the ERKO stroma + wild-type epithelium, but normal ductal growth and branching was observed in the wildtype stroma + ERKO epithelium. These results suggest the requirement for stromal ER in normal ductal development in the mouse and indicate that the actions of estrogen on ductal proliferation are mediated via a paracrine mechanism. However, most recently, the importance of stromal vs. epithelial $\mathrm{ER} \alpha$ was reexamined using a new knockout mouse strain in which $\mathrm{ER} \alpha$ signaling is completely blocked, as it was determined that the ERKO mice used by Cunha et al. (1997) produce an $\mathrm{ER} \alpha$ splice variant with transactivation activity in the carboxy-terminal ligand-binding domain (Mallepell et al., 2006). The new $\mathrm{ER} \alpha^{-/}$mice fail to exhibit pubertal ductal development, in agreement with previous work, yet transplantation studies indicate that epithelial rather than stromal ER $\alpha$ is critical for mediating the effects of estrogen on ductal development. In their experiments, Mallepell and colleagues found that $\mathrm{ER} \alpha^{-1-}$ epithelium transplanted into wild-type stroma showed no ductal proliferation, whereas wild-type epithelium $+\mathrm{ER} \alpha^{-/}$stroma exhibited normal ductal elongation. These recent findings contradict earlier work in the ERKO mouse but are more consistent with proposed mechanisms in humans and cattle.

As discussed earlier, $\mathrm{ER} \alpha$ is expressed almost exclusively in the mammary epithelium of the human (Anderson and Clarke, 2004) and cow (Capuco et al., 2002a; Schams et al., 2003), although immunolocalization of $\mathrm{ER} \alpha$ in the occasional stromal fibroblast in heifers (Schams et al., 2003) and in primary cultures of human mammary fibroblasts (Malet et al., 1991) has been demonstrated. Most recently, ER $\alpha$ expression by approximately $30 \%$ of adipocytes and fibroblasts within the bovine mammary fat pad of prepubertal heifers was demonstrated by immunohistochemistry (M. J. Meyer, unpublished data). In addition, abundance of $\mathrm{ER} \alpha$ transcripts in mammary stroma, as determined by realtime quantitative reverse transcription PCR, was equivalent to quantities measured in parenchyma and reached values similar to those previously reported in the parenchyma of adult cows (Connor et al., 2005). These findings suggest that the opportunity exists for stromal ER $\alpha$ to mediate estrogen effects in the human and bovine mammary glands. However, Malet et al. (1991) found that unlike epithelial ER $\alpha$, expression of $\mathrm{ER} \alpha$ in human fibroblasts was unresponsive to estrogen treatment. In contrast, Woodward et al. (1993) were able to demonstrate a proliferative response of bovine fibroblasts to estrogen treatment, but only among those cells in close proximity to epithelial cells. Furthermore, the proliferative response in fibroblasts was preceded by epithelial cell proliferation. Therefore, these results and the scarcity of ER $\alpha$ protein expression in the bovine stroma suggest that the proliferative signal does not originate from stromal $\mathrm{ER} \alpha$ in this species but appears to be mediated by epithelial ER $\alpha$. Additional research is needed to completely characterize the relationship between stromal ER $\alpha$ expression and epithelial cell growth in cattle.

Despite an inconclusive role of stromal $\mathrm{ER} \alpha$ in mediating epithelial proliferation in the cow and human, it 
does appear that stromal- and epithelial-derived growth factor intermediates contribute to stimulating epithelial cell proliferation in most species. For example, proliferating mammary epithelial cells themselves do not express ER $\alpha$ or PR, but lie near receptor-positive epithelial cells (Clarke et al., 1997; Conneely et al., 2001; Capuco et al., 2002a), suggesting the presence of paracrine intermediates. Furthermore, in the prepubertal heifer, epithelial cell proliferation in response to estrogen treatment is greatest in parenchyma that is adjacent to the mammary fat pad (Capuco et al., 2002a). Finally, through the use of transgenic murine $\mathrm{ER} \alpha^{-1-}$ epithelial cells, which turn blue upon appropriate staining, Mallepell et al. (2006) demonstrated that $\mathrm{ER}^{-/-}$ epithelial cells + wild-type epithelium transplanted into cleared fat pad of wild-type recipients results in proliferation of $\mathrm{ER}^{-/-}$cells within all mammary structures, including ducts, side branches, and myoepithelial compartments. These results provide compelling evidence that estrogen acts through a paracrine mechanism to stimulate mammary cell proliferation in neighboring ER-negative cells.

Numerous studies have investigated the roles of such factors as IGF-I, hepatocyte growth factor, keratinocyte growth factor, fibroblast growth factors, and epidermal growth factor as paracrine intermediates involved in mammary development (Hovey et al., 1999; Imagawa et al., 2002; Anderson and Clarke, 2004). Indeed, these growth factors are expressed in stromal cells of humans, ruminants, and rodents (Hovey et al., 1999). Likewise, Wnt-4, a signaling molecule under PR-A and PR-B regulation, has recently been identified as a putative paracrine mediator of progesterone on mammary cell proliferation (Conneely et al., 2001; Mulac-Jericevic and Conneely, 2004) and amphiregulin, a gene highly responsive to estrogen, has been proposed as a paracrine mediator of ER $\alpha$ signaling (Mallepell et al., 2006; Sternlicht et al., 2006).

Recently, we examined the abundance of IGF-I mRNA in the mammary parenchyma and fat pad of prepubertal heifers from birth to puberty. We found that expression of IGF-I was greater in mammary fat pad than in parenchyma and that IGF-I expression in both compartments coincided with epithelial cell proliferation (M. J. Meyer, unpublished data). These results support the hypothesis that stromal-derived IGF-I may mediate a portion of the proliferative effects of estrogen in mammary epithelial cells in ruminants. In addition, we recently demonstrated that estrogen treatment in the prepubertal heifer results in increased IGF-I expression in the mammary fat pad that is greater than the increase in the parenchyma (Meyer et al., 2006), consistent with previous studies in ewe lambs (Hovey et al., 1998). A model for the mechanisms of estrogen
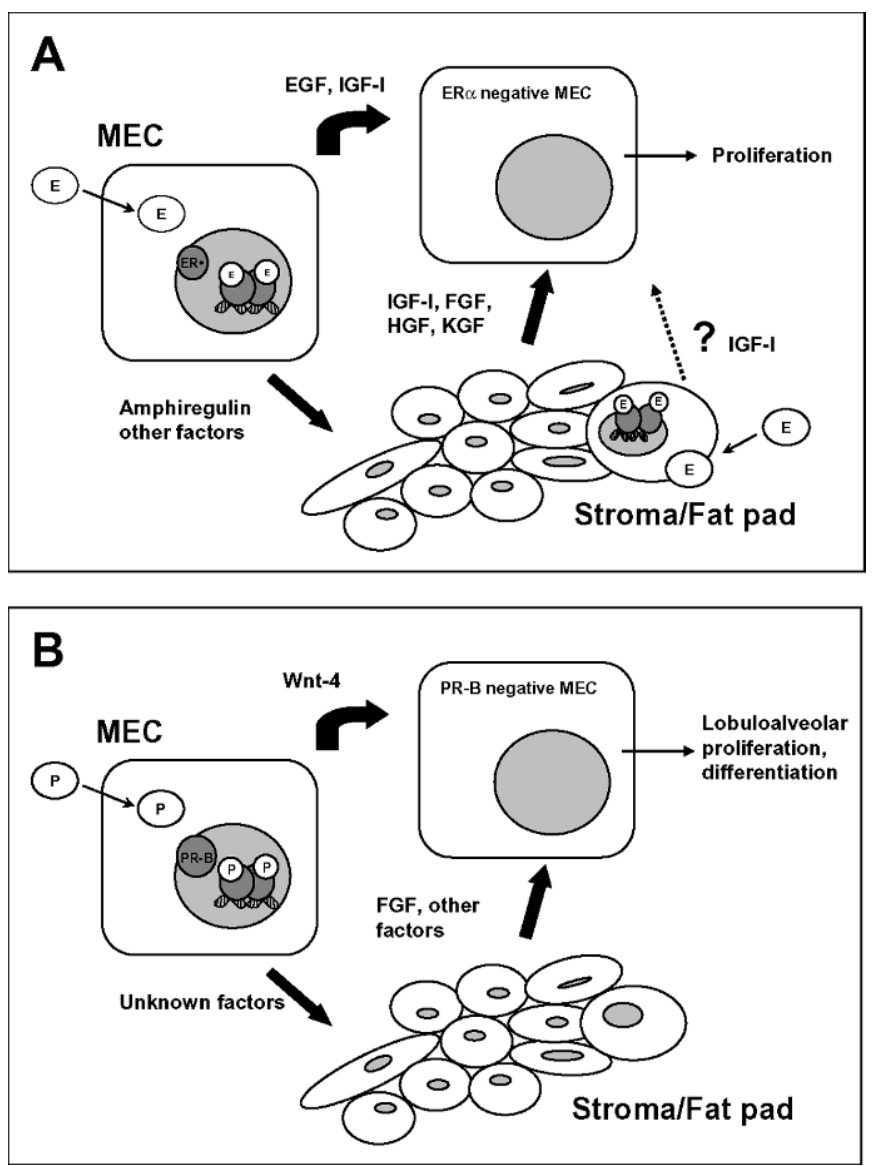

Figure 2. Proposed paracrine pathway of (A) estrogen and (B) progesterone action on mammary epithelial cell proliferation in ruminants. $\mathrm{E}=$ estrogen; $\mathrm{EGF}=$ epidermal growth factor; $\mathrm{ER} \alpha=$ estrogen receptor $\alpha ; \mathrm{FGF}=$ fibroblast growth factors; $\mathrm{HGF}=$ hepatocyte growth factor; IGF-I = insulin-like growth factor-I; KGF = keratinocyte growth factor; $\mathrm{MEC}=$ mammary epithelial cell; $\mathrm{P}=$ progesterone; $\mathrm{PR}-\mathrm{B}=$ progesterone receptor $\mathrm{B}$; Wnt- 4 = signaling molecule.

and progesterone action on mammary epithelial growth in humans was proposed by Anderson and Clarke (2004). In their model, estrogen and progesterone bind to their epithelial receptors (likely ER $\alpha$ and PR-B, respectively), which then stimulate the growth of nearby epithelial cells via epithelial-derived factors (e.g., epidermal growth factor and Wnt-4) and stromal-derived factors, such as fibroblast growth factors and IGF-I. Based on their model and a hypothesis presented by Mallepell et al. (2006) on paracrine signaling via ER $\alpha$, a proposed pathway of ovarian steroid hormone action on the mammary gland in ruminants is presented in Figure 2.

\section{Using Microarrays to Understand Estrogen Function in the Mammary Gland}

The complete sequencing of several mammalian genomes and the development of microarray technologies 
have greatly facilitated our ability to examine global changes in gene expression in the mammary gland in response to the steroid environment. For instance, $\mathrm{Ru}$ dolph et al. (2003) used a cluster analysis of mammary gland gene expression profiles from d 12 of pregnancy through $\mathrm{d} 9$ of lactation in the mouse to develop a molecular model of progesterone regulation of gene expression during mammary secretory differentiation and activation. The authors proposed a mechanism by which progesterone suppresses milk secretion during late pregnancy via activation of $T G F-\beta, W n t-5 b$, and IGFBP5 that block the prolactin- and IGF-I-signaling pathways. The decline in progesterone near parturition then permits prolactin and IGF-I to stimulate milk secretion through AKT1 activation, and permits lipid synthesis through stimulation of SREBP-1 and other fat synthesis genes. Future studies using similar approaches will be useful for developing hypotheses regarding molecular control of other mammary gland functions and physiological stages of development.

Furthermore, microarrays were recently used to identify estrogen-responsive genes and direct $\mathrm{ER} \alpha$ gene targets in a human $\mathrm{ER}^{+}$breast tumor cell line (Lin et al., 2004). Direct ER gene targets were identified by selecting those genes whose responses were sensitive to antiestrogen treatment and unaffected by treatment with cyclohexamide (a protein synthesis inhibitor). This study revealed some interesting results: 1) few direct ER gene targets (6\%) identified in humans and rodents share conserved regulatory regions and estrogen response elements in their promoters, despite an approximated $85 \%$ sequence similarity in their coding regions; 2 ) only $36 \%$ of estrogen-responsive genes identified were regulated via ER, suggesting transcriptional activity of a number of genes acting through ER-independent signaling pathways; and 3 ) only about $50 \%$ of identified ER target genes had identifiable estrogen response elements in their upstream promoters, suggesting a large proportion of genes acting through nonclassical pathways. Thus, microarray approaches can be useful for identifying specific gene targets of steroid hormones, as well as for gaining insight into their transcriptional regulation. Comparative studies will also benefit from microarray approaches as more genome sequences become available.

The recent availability of bovine genomic sequence information has been useful for cataloging steroid-responsive genes in the mammary gland of cattle. We have recently used a high-density bovine oligonucleotide array representing $>45,000$ potential transcripts to identify over 124 genes influenced by estrogen treatment in the mammary parenchyma and fat pad of prepubertal dairy heifers (Li et al., 2006). Of interest, 76\% of these genes were not previously reported to be estro- gen responsive in other species (Tang et al., 2004; Jin et al., 2005), and only 17 genes were commonly regulated in both parenchymal and fat pad compartments, indicating substantial differential regulation between the 2 tissue types. In addition, estrogen treatment generally resulted in an increase in target gene expression because only $3 \%$ of estrogen-responsive genes were down-regulated. This is considerably different from values reported by Lin et al. (2004), who indicated that 28 to $41 \%$ of estrogen-responsive genes were down-regulated in a human breast tumor cell line following estrogen treatment. These differences may be species specific or may be a result of variation in genes represented on the arrays, experimental design (i.e., estrogen treatment, sampling times, or in vivo vs. in vitro), normal vs. cancerous cells, or statistical analyses used to determine significance thresholds.

In the parenchyma, we also observed that genes associated with epithelial cell proliferation and extracellular matrix turnover were up-regulated by estrogen treatment, consistent with the role of estrogen in prepubertal ductal growth. In the mammary fat pad, increased expression of genes associated with increased extracellular matrix deposition and remodeling indicated changes that may be necessary to permit penetration of mammary ducts into the surrounding fat pad. In addition, increased expression of $I G F 1$ and the stem cell growth factor precursor CLEC11A in the fat pad supported the role of the fat pad as a source of paracrine mediators of epithelial cell proliferation. In both mammary tissue compartments, increased expression of putative stem cell markers or regulators also suggested impacts of estrogen on mammary stem cells or progenitor cell populations. Additional work using techniques such as laser capture microdissection and in situ hybridization will be needed to further characterize expression profiles of individual mammary cell types and understand cross talk among them.

Finally, a cursory examination of estrogen-responsive genes in human, rodent, and bovine mammary glands suggests that estrogen action in the bovine gland may also be mediated by gene family members that differ from those identified as estrogen responsive in humans and rodents. For instance, keratin 1 was identified as an estrogen-responsive gene in bovines ( $\mathrm{Li}$ et al., 2006), whereas keratin 19 was estrogen responsive in humans and rodents (Jin et al., 2005). Likewise, differences between bovines, and humans and rodents were observed in estrogen responsiveness of specific dual specificity phosphatase, cathepsin, glutamate receptor, centromere protein, $N$-acetyl galactosaminyl transferase, high mobility group box, and PDZ domaincontaining gene family members (Tang et al., 2004; Jin et al., 2005; Li et al., 2006). Global analysis of gene 
expression using high-throughput methods such as microarray should be useful for future studies characterizing differences in steroid hormone action in the mammary gland across species.

\section{SUMMARY}

Advances in the field of genomics have had a significant impact on our current understanding of the local regulation of mammary gland development and function by the ovarian steroids. For instance, DNA cloning and sequencing have led to the discovery of novel ovarian steroid receptors (e.g., $\mathrm{ER} \beta$, its splice variants, and $\mathrm{mPR}$ ) and the development of molecular reagents to study the expression of gene transcripts of interest (e.g., effects of steroid treatment on the expression of growth factor intermediates and global gene expression using microarrays). Further, the development of genetically modified mice has enabled researchers to examine the functions of individual receptors on mammary development (e.g., PR-A and PR-B knockout and overexpression), as well as their functional relevance within particular mammary tissues (e.g., stromal vs. parenchymal expression of $\mathrm{ER} \alpha$ ). Genome sequencing efforts have also permitted comparative studies of gene structure and regulation in silico, resulting in the discovery of critical species differences (e.g., few conserved regulatory elements in estrogen-responsive gene promoters between humans and rodents, and variation in estrogen-responsive gene family members among humans, rodents, and bovines). Future studies will continue to expand our understanding of gene regulation within the mammary gland and should enhance our ability to promote mammary development and the lactation performance of dairy cattle.

\section{REFERENCES}

Anderson, E. 2002. The role of oestrogen and progesterone receptors in human mammary development and tumorigenesis. Breast Cancer Res. 4:197-201.

Anderson, E., and R. B. Clarke. 2004. Steroid receptors and cell cycle in normal mammary epithelium. J. Mammary Gland Biol. Neoplasia 9:3-13.

Aranda, A., and A. Pascual. 2001. Nuclear hormone receptors and gene expression. Physiol. Rev. 81:1269-1304.

Bocchinfuso, W. P., J. K. Lindzey, S. C. Hewitt, J. A. Clark, P. H. Myers, R. Cooper, and K. S. Korach. 2000. Induction of mammary gland development in estrogen receptor- $\alpha$ knockout mice. Endocrinology 141:2982-2994.

Capuco, A. V., S. Ellis, D. L. Wood, R. M. Akers, and W. Garrett. 2002a. Postnatal mammary ductal growth: Three-dimensional imaging of cell proliferation, effects of estrogen treatment and expression of steroid receptors in prepubertal calves. Tissue Cell 34:143-154.

Capuco, A. V., P. A. Feldhoff, R. M. Akers, J. L. Wittliff, and H. A. Tucker. 1982. Progestin binding in mammary tissue of prepartum, nonlactating and postpartum, lactating cows. Steroids 40:503-517.
Capuco, A. V., M. Li, E. Long, S. Ren, K. S. Hruska, K. Schorr, and P. A. Furth. 2002b. Concurrent pregnancy retards mammary involution: Effects on apoptosis and proliferation of the mammary epithelium after forced weaning of mice. Biol. Reprod. 66:1471-1476.

Cheng, G., Y. Li, Y. Omoto, Y. Wang, T. Berg, M. Nord, P. Vihko, M. Warner, Y. S. Piao, and J. A. Gustafsson. 2005. Differential regulation of estrogen receptor (ER) and $\mathrm{ER} \beta$ in primate mammary gland. J. Clin. Endocrinol. Metab. 90:435-444.

Clark, R. B., A. Howell, C. S. Potten, and E. Anderson. 1997. Dissociation between steroid receptor expression and cell proliferation in the human breast. Cancer Res. 57:4987-4991.

Conneely, O. M., B. Mulac-Jericevic, J. P. Lydon, and F. J. De Mayo. 2001. Reproductive functions of the progesterone receptor isoforms: Lessons from knock-out mice. Mol. Cell. Endocrinol. 179:97-103.

Connor, E. E., D. L. Wood, T. S. Sonstegard, A. F. Mota, G. L. Bennett, J. L. Williams, and A. V. Capuco. 2005. Chromosomal mapping and quantitative analysis of estrogen-related receptor $\alpha$-1, estrogen receptors $\alpha$ and $\beta$ and progesterone receptor in the bovine mammary gland. J. Endocrinol. 185:593-603.

Cowie, A., I. A. Forsyth, and I. C. Hart. 1980. Hormonal control of lactation. Pages 1-275 in Monographs on Endocrinology. Vol. 15. Springer-Verlag, Berlin, Germany.

Cunha, G. R., P. Young, Y. K. Hom, P. S. Cooke, J. A. Taylor, and D. B. Lubahn. 1997. Elucidation of a role for stromal steroid hormone receptors in mammary gland growth and development using tissue recombinants. J. Mammary Gland Biol. Neoplasia 2:393-402.

Ellis, S., T. B. McFadden, and R. M. Akers. 1998. Prepubertal ovine mammary development is unaffected by ovariectomy. Domest. Anim. Endocrinol. 15:217-225.

Falkenstein, E., H. C. Tillmann, M. Christ, M. Feuring, and M. Wehling. 2000. Multiple actions of steroid hormones-A focus on rapid, nongenomic effects. Pharmacol. Rev. 52:513-555.

Fannon, S. A., R. M. Vidaver, and S. A. Marts. 2001. An abridged history of sex steroid hormone receptor action. J. Appl. Physiol. 91:1854-1859.

Fendrick, J. L., A. M. Raafat, and S. Z. Haslam. 1998. Mammary gland growth and development from the postnatal period to postmenopause: Ovarian steroid receptor ontogeny and regulation in the mouse. J. Mammary Gland Biol. Neoplasia 3:7-22.

Forsyth, I. A. 1986. Variation among species in the endocrine control of mammary growth and function: The roles of prolactin, growth hormone, and placental lactogen. J. Dairy Sci. 69:886-903.

Funakoshi, T., A. Yanai, K. Shinoda, M. M. Kawano, and Y. Mizukami. 2006. G protein-coupled receptor 30 is an estrogen receptor in the plasma membrane. Biochem. Biophys. Res. Commun. 346:904-910.

Hall, J. M., and D. P. McDonnell. 1999. The estrogen receptor $\beta$ isoform $(\mathrm{ER} \beta)$ of the human estrogen receptor modulates $\mathrm{ER} \alpha$ transcriptional activity and is a key regulator of the cellular response to estrogen and antiestrogens. Endocrinology 140:55665578.

Hovey, R. C., H. W. Davey, D. D. Mackenzie, and T. B. McFadden. 1998. Ontogeny and epithelial-stromal interactions regulate IGF expression in the ovine mammary gland. Mol. Cell. Endocrinol. 136:139-144.

Hovey, R. C., T. B. McFadden, and R. M. Akers. 1999. Regulation of mammary gland growth and morphogenesis by the mammary fat pad: A species comparison. J. Mammary Gland Biol. Neoplasia $4: 53-68$.

Hovey, R. C., J. F. Trott, E. Ginsburg, A. Goldhar, M. M. Sasaki, S. J. Fountain, K. Sundararajan, and B. K. Vonderhaar. 2001. Transcriptional and spatiotemporal regulation of prolactin receptor mRNA and cooperativity with progesterone receptor function during ductal branch growth in the mammary gland. Dev. Dyn. 222:192-205.

Hovey, R. C., J. F. Trott, and B. K. Vonderhaar. 2002. Establishing a framework for the functional mammary gland: From endocrinology to morphology. J. Mammary Gland Biol. Neoplasia 7:17-38. 
Imagawa, W., V. K. Pedchenko, J. Helber, and H. Zhang. 2002. Hormone/growth factor interactions mediating epithelial/stromal communication in mammary gland development and carcinogenesis. J. Steroid Biochem. Mol. Biol. 80:213-230.

Jin, V. X., H. Sun, T. T. Pohar, S. Liyanarachchi, S. K. Palaniswamy, T. H. Huang, and R. V. Davuluri. 2005. ERTargetDB: An integral information resource of transcription regulation of estrogen receptor target genes. J. Mol. Endocrinol. 35:225-230.

Kastner, P., A. Krust, B. Turcotte, U. Stropp, L. Tora, H. Gronemeyer, and P. Chambon. 1990. Two distinct estrogen-regulated promoters generate transcripts encoding the two functionally different human progesterone receptor forms A and B. EMBO J. 9:1603-1614.

Kraus, W. L., M. M. Montano, and B. S. Katzenellenbogen. 1993. Cloning of the rat progesterone receptor gene $5^{\prime}$-region and identification of two functionally distinct promoters. Mol. Endocrinol. 7:1603-1616.

Kushner, P. J., D. A. Agard, G. L. Greene, T. S. Scanlan, A. K. Shiau, R. M. Uht, and P. Webb. 2000. Estrogen receptor pathways to AP-1. J. Steroid Biochem. Mol. Biol. 74:311-317.

Lazar, M. A. 2002. Mechanism of action of hormones that act on nuclear receptors. Pages 35-44 in Williams Textbook of Endocrinology, 10th ed. P. R. Larsen, H. M. Kronenberg, S. Melmed, and K. S. Polonsky, ed. Elsevier, Oxford, UK.

Li, R. W., M. J. Meyer, C. P. Van Tassell, T. S. Sonstegard, E. E. Connor, M. E. Van Amburgh, Y. R. Boisclair, and A. V. Capuco. 2006. Identification of estrogen-responsive genes in the parenchyma and fat pad of the bovine mammary gland by microarray analysis. Physiol. Genomics 27:42-53.

Lin, C. Y., A. Strom, V. B. Vega, S. L. Kong, A. L. Yeo, J. S. Thomsen, W. C. Chan, B. Doray, D. K. Bangarusamy, A. Ramasamy, L. A. Vergara, S. Tang, A. Chong, V. B. Bajic, L. D. Miller, J. A. Gustafsson, and E. T. Liu. 2004. Discovery of estrogen receptor $\alpha$ target genes and response elements in breast tumor cells. Genome Biol. 5:R66.

Liu, M. M., C. Albanese, C. M. Anderson, K. Hilty, P. Webb, R. M. Uht, R. H. Price, Jr., R. G. Pestell, and P. J. Kushner. 2002. Opposing action of estrogen receptors $\alpha$ and $\beta$ on cyclin D1 gene expression. J. Biol. Chem. 277:24353-24360.

Lydon, J. P., L. Sivaraman, and O. M. Conneely. 2000. A reappraisal of progesterone action in the mammary gland. J. Mammary Gland Biol. Neoplasia 5:325-338.

Malet, C., A. Gompel, H. Yaneva, H. Cren, N. Fidji, I. Mowszowicz, F. Kuttenn, and P. Mauvais-Jarvis. 1991. Estradiol and progesterone receptors in cultured normal human breast epithelial cells and fibroblasts: Immunocytochemical studies. J. Clin. Endocrinol. Metab. 73:8-17.

Mallepell, S., A. Krust, P. Chambon, and C. Brisken. 2006. Paracrine signaling through the epithelial estrogen receptor $\alpha$ is required for proliferation and morphogenesis in the mammary gland. Proc. Natl. Acad. Sci. USA 103:2196-2201.

Manavathi, B., and R. Kumar. 2006. Steering estrogen signals from the plasma membrane to the nucleus: Two sides of the coin. J. Cell. Physiol. 207:594-604.

Meyer, M. J., A. V. Capuco, Y. R. Boisclair, and M. E. Van Amburgh. 2006. Estrogen-dependent responses of the mammary fat pad in prepubertal dairy heifers. J. Endocrinol. 190:819-827.

Mulac-Jericevic, B., and O. M. Conneely. 2004. Reproductive tissue selective actions of progesterone receptors. Reproduction 128:139-146.

Neville, M. C., T. B. McFadden, and I. Forsyth. 2002. Hormonal regulation of mammary differentiation and milk secretion. J. Mammary Gland Biol. Neoplasia 7:49-66.

Pfaffl, M. W., I. G. Lange, A. Daxenberger, and H. H. D. Meyer. 2001. Tissue-specific expression pattern of estrogen receptors (ER): Quantification of $\operatorname{ER} \alpha$ and $\operatorname{ER} \beta$ mRNA with real-time RT-PCR. APMIS 109:345-355.

Rae, M. T., G. S. Menzies, and T. A. Bramley. 1998. Bovine ovarian non-genomic progesterone binding sites: Presence in follicular and luteal cell membranes. J. Endocrinol. 159:413-427.

Rudolph, M. C., J. L. McManaman, L. Hunter, T. Phang, and M. C. Neville. 2003. Functional development of the mammary gland:
Use of expression profiling and trajectory clustering to reveal changes in gene expression during pregnancy, lactation, and involution. J. Mammary Gland Biol. Neoplasia 8:287-307.

Saji, S., Y. Omoto, C. Shimizu, M. Warner, Y. Hayashi, S. Horiguchi, T. Watanabe, S. Hayashi, J. A. Gustafsson, and M. Toi. 2002. Expression of estrogen receptor $(\mathrm{ER})(\beta)$ cx protein in $\operatorname{ER}(\alpha)$-positive breast cancer: Specific correlation with progesterone receptor. Cancer Res. 62:4849-4853.

Saji, S., H. Sakaguchi, S. Andersson, M. Warner, and J. Gustafsson. 2001. Quantitative analysis of estrogen receptor proteins in rat mammary gland. Endocrinology 142:3177-3186.

Schams, D., S. Kohlenberg, W. Amselgruber, B. Berisha, M. W. Pfaffl, and F. Sinowatz. 2003. Expression and localization of oestrogen and progesterone receptors in the bovine mammary gland during development, function and involution. J. Endocrinol. 177:305317.

Schmidt, B. M., W. Schmidt, D. Gerdes, M. Feuring, E. Falkenstein, M. Christ, and M. Wehling. 2000. Rapid, nongenomic steroid actions: A new age? Front. Neuroendocrinol. 21:57-94.

Shyamala, G. 1999. Progesterone signaling and mammary gland morphogenesis. J. Mammary Gland Biol. Neoplasia 4:89-104.

Shyamala, G., Y.-C. Chou, S. G. Louie, R. C. Guzman, G. H. Smith, and S. Nandi. 2002. Cellular expression of estrogen and progesterone receptors in mammary glands: Regulation by hormones, development and aging. J. Steroid Biochem. Mol. Biol. 80:137-148.

Shyamala, G., S. G. Louie, I. G. Camarillo, and F. Talamantes. 1999. The progesterone receptor and its isoforms in mammary development. Mol. Genet. Metab. 68:182-190.

Shyamala, G., W. Schneider, and D. Schott. 1990. Developmental regulation of murine mammary progesterone receptor gene expression. Endocrinology 126:2882-2889.

Silberstein, G. B. 2001. Postnatal mammary gland morphogenesis. Microsc. Res. Tech. 52:155-162.

Silberstein, G. B., K. Van Horn, G. Shyamala, and C. W. Daniel. 1994. Essential role of endogenous estrogen in directly stimulating mammary growth demonstrated by implants containing pure antiestrogens. Endocrinology 134:84-90.

Spiers, V., G. P. Skliris, S. E. Burdall, and P. J. Carder. 2002. Distinct expression patterns of $\mathrm{ER} \alpha$ and $\mathrm{ER} \beta$ in normal human mammary gland. J. Clin. Pathol. 55:371-374.

Sternlicht, M. D., S. W. Sunnarborg, H. Kouros-Mehr, Y. Yu, D. C. Lee, and Z. Werb. 2006. Mammary ductal morphogenesis requires paracrine activation of stromal EGFR via ADAM17-dependent shedding of epithelial amphiregulin. Development 132:39233933 .

Tang, S., H. Han, and V. B. Bajic. 2004. ERGDB: Estrogen responsive genes database. Nucleic Acids Res. 32:D533-D536.

Taylor, A. H., P. C. McParland, D. J. Taylor, and S. C. Bell. 2006. The progesterone receptor in human term amniochorion and placenta is isoform C. Endocrinology 147:687-693.

Thomas, P., Y. Pang, E. J. Filardo, and J. Dong. 2005. Identity of an estrogen membrane receptor coupled to a $G$ protein in human breast cancer cells. Endocrinology 146:624-632.

Tucker, H. A. 2000. Hormones, mammary growth, and lactation: A 41-year perspective. J. Dairy Sci. 83:874-884.

Turner, C. W., H. Yamamoto, and H. L. Ruppert. 1956. The experimental induction of growth of the cow's udder and the initiation of milk secretion. J. Dairy Sci. 39:1717-1723.

Umayahara, Y., R. Kawamori, H. Watada, E. Imano, N. Iwama, T. Morishima, Y. Yamasaki, Y. Kajimoto, and T. Kamada. 1994 Estrogen regulation of the insulin-like growth factor I gene transcription involves an AP-1 enhancer. J. Biol. Chem. 269:16433-16442.

Walker, V. R., and K. S. Korach. 2004. Estrogen receptor knockout mice as a model for endocrine research. ILAR J. 45:455-461.

Wallace, C. 1953. Observations on mammary development in calves and lambs. J. Agric. Sci. 43:413-421.

Warner, M., and J.-A. Gustafsson. 2006. Nongenomic effects of estrogen: Why all the uncertainty? Steroids 71:91-95.

Wei, L. L., C. Gonzalez-Aller, W. M. Wood, L. A. Miller, and K. B. Horwitz. 1990. 5' Heterogeneity in human progesterone receptor 
transcripts predicts a new amino-terminal truncated "C"-receptor and unique A-receptor messages. Mol. Endocrinol. 4:1833-1840.

Wei, L. L., P. Hawkins, C. Baker, B. Norris, P. L. Sheridan, and P. G. Quinn. 1996. An amino-terminal truncated progesterone receptor isoform, PRc, enhances progestin-induced transcriptional activity. Mol. Endocrinol. 10:1379-1387.

Wei, L. L., B. M. Norris, and C. J. Baker. 1997. An N-terminally truncated third progesterone receptor protein, $\mathrm{PR}(\mathrm{C})$, forms heterodimers with $\mathrm{PR}(\mathrm{B})$ but interferes in $\mathrm{PR}(\mathrm{B})$-DNA binding. J. Steroid Biochem. Mol. Biol. 62:287-297.

Woodward, T. L., W. E. Beal, and R. M. Akers. 1993. Cell interactions in initiation of mammary epithelial proliferation by oestradiol and progesterone in prepubertal heifers. J. Endocrinol. 136:149-157.
Woodward, T. L., J. W. Xie, and S. Z. Haslam. 1998. The role of mammary stroma in modulating the proliferative response to ovarian hormones in the normal mammary gland. J. Mammary Gland Biol. Neoplasia 3:117-131.

Zeps, N., J. M. Bentel, J. M. Papadimitriou, and H. J. S. Dawkins. 1999. Murine progesterone receptor expression in proliferating mammary epithelial cells during normal pubertal development and adult estrous cycle: Association with $\mathrm{ER} \alpha$ and $\mathrm{ER} \beta$ status. J. Histochem. Cytochem. 47:1323-1330.

Zhu, Y., J. Bond, and P. Thomas. 2003. Identification, classification, and partial characterization of genes in humans and other vertebrates homologous to a fish membrane progestin receptor. Proc. Natl. Acad. Sci. USA 100:2237-2242. 